\title{
Structure and characterization of a biosurfactant produced by Pseudomonas aeruginosa strain KO9
}

\author{
Zheng Li, Chaocheng Zhao*, Yunbo Zhang, Dongfeng Zhao \\ College of Chemistry and Chemical Engineering \\ China University of Petroleum \\ Qingdao, P. R. China \\ *zhao8021@sina.com
}

\begin{abstract}
Pseudomonas aeruginosa strain KO9, isolated from petroleum-contaminated soil in Karamay oil filed (China) was used to produce biosurfactant. The biosurfactant could reduce surface tension to $28 \mathrm{mN} / \mathrm{m}$ and emulsified diesel up to $E_{24}$ of $81 \%$ with a critical micelle concentration of approximately 85.82 $\mathrm{mg} / \mathrm{L}$. The dried biosurfactant was light yellow powder, and the yield was $1.0866 \mathrm{~g} / \mathrm{L}$. Fourier transform infrared (FT-IR) spectrum of extracted biosurfactant indicates the key component is glycolipid primarily consisting of lipid and carbohydrate. The crude biosurfactant showed comparable stability over a wide range of $\mathrm{pH}$, temperatures and high salt concentrations, as compared to the two commercial surfactants, sodium dodecyl sulfate (SDS) and cetyltrimethyl ammonium bromide (CTAB). It has potential for use in a variety of biotechnological and industrial applications.
\end{abstract}

Keywords-Pseudomonas aeruginosa; Biosurfactants; Glycolipid; Surface tension; Emulsification

\section{INTRODUCTION}

Surfactants can be classified into two main groups: synthetic surfactants and biosurfactants. Biosurfactants are amphiphilic compounds with pronounced surface and emulsifying activities produced by microorganisms, such as bacteria, fungi, and yeast ${ }^{[1,2]}$. When compared to synthetic surfactants, biosurfactants have several advantages, including high biodegradability, low toxicity, low irritancy, and compatibility with human $\operatorname{skin}^{[3,4]}$. Therefore, biosurfactants appear preferable for the environmental applications and have a potential use in medical, cosmetic, and food industries, etc ${ }^{[5]}$.

Biosurfactants comprise a diverse group of surface-active molecules which include glycolipids, lipopeptides, polysaccharide-protein complexes, protein-like substances, lipopolysaccharides, phospholipids, fatty acids and neutral lipids ${ }^{[1,6]}$. Glycolipids are the most common biosurfactants that have been isolated and studied among these groups. It is mainly produced by Pseudomonas aeruginosa strains.

In this study, Pseudomonas aeruginosa KO9, isolated from petroleum-contaminated soil in Karamay oil filed (China), was used to produce a biosurfactant. The chemical structures of the components in the crude biosurfactant were preliminarily determined by using Fourier transform infrared (FT-IR) spectroscopy, and their physicochemical properties were investigated in a comparison with those of the synthetic surfactants, including SDS and CTAB.

\section{MATERIALS AND METHODS}

\section{A. Bacterial strain and culture growth conditions}

$P$. aeruginosa strain KO9 was isolated from petroleumcontaminated soil in Karamay oil filed. The isolated strain was maintained on nutrient agar slants at $30{ }^{\circ} \mathrm{C}$ and was subcultured every 2 weeks. The medium used to grow $P$. aeruginosa KO9 strain was a mineral salts (MS) medium consisting of $\mathrm{CaCl}_{2}(7 \mu \mathrm{M}), \mathrm{MgSO}_{4} \cdot 7 \mathrm{H}_{2} \mathrm{O}(800 \mu \mathrm{M}), \mathrm{NH}_{4} \mathrm{NO}_{3}$ $(50 \mathrm{mM}), \quad \mathrm{KH}_{2} \mathrm{PO}_{4}(30 \mathrm{mM}), \mathrm{Na}_{2} \mathrm{HPO}_{4}(40 \mathrm{mM})$, and $\mathrm{FeSO}_{4} \cdot 7 \mathrm{H}_{2} \mathrm{O}(2 \mu \mathrm{M})$. A glucose mineral salts (GMS) medium is defined as glucose (5\%)-supplemented MS medium. The $\mathrm{pH}$ of GMS medium was initially adjusted to 7.0 by $1.0 \mathrm{M} \mathrm{HCl}$.

\section{B. Biosurfactant Extraction}

The biosurfactant produced by strain KO9 were extracted following O. Pornsunthorntawee et al. $(2008)^{[7]}$.

\section{Preliminary characterization of biosurfactant}

The chemical structures of the components in the crude biosurfactant sample were preliminarily determined by using Fourier transform infrared (FT-IR) spectroscopy ${ }^{[8]}$.

\section{Surface tension assay}

The surface tension (ST) measurement of aqueous solution at different surfactant concentrations was determined in a Surface Tensiometer (Model CBVP-A3, FACE, Japan), using the Plate method. The critical micelle concentration (CMC) was determined from the break point of the surface tension versus its log of bulk concentration curve. All measurements were carried out at $25 \pm 1{ }^{\circ} \mathrm{C}$ and repeated three times, then average values were obtained.

\section{E. Emulsion test assay}

A mixture of $4 \mathrm{ml}$ supernatant and $6 \mathrm{ml}$ diesel was vortexed for $2 \mathrm{~min}$ and the height of emulsion layer was measured after $24 \mathrm{~h}$ to determine the emulsion index $\left(\mathrm{E}_{24}\right)^{[9]}$.

$$
\mathrm{E}_{24}(\%)=\frac{\text { The height of emulsion layer }}{\text { The height of total solution }} \times 100
$$

\section{F. Stability testing}

The crude biosurfactant sample, sodium dodecyl sulfate (SDS) and cetyltrimethyl ammonium bromide (CTAB) were 
prepared at the CMCs for stability test. The prepared surfactant solutions were incubated in a $90{ }^{\circ} \mathrm{C}$ water bath at different time intervals before cooling to room temperature. The $\mathrm{pH}$ stability was investigated by adjusting the solutions to different $\mathrm{pH}$ values. The effect of salinity on the activity of the surfactants was investigated by adding $\mathrm{NaCl}$ of different concentrations. The surface tension and emulsion index were measured and used to indicate the stability for thermal, $\mathrm{pH}$ and salinity stability testing.

\section{RESULTS AND DISCUSSIONS}

\section{A. Physicochemical properties}

The dependence of surface tension on the biosurfactant concentration studied is shown in Fig. 1. Surface tension decreased rapidly from 75.2 to $28.4 \mathrm{mN} / \mathrm{m}$ with increases in the biosurfactant concentration up to $108.67 \mathrm{mg} / \mathrm{L}$. Further increases in the biosurfactant concentration, only slowly reduced the surface tension from 28.4 to $26.6 \mathrm{mN} / \mathrm{m}$. The $\mathrm{CMC}$ value was determined to be $85.82 \mathrm{mg} / \mathrm{L}$, from the intersection of regression lines that describe two parts of the curve.

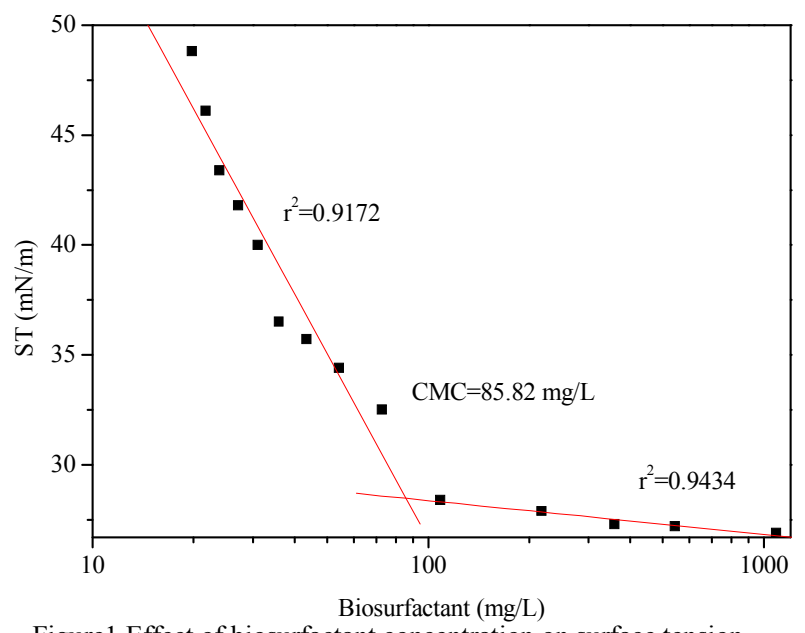

Figure1 Effect of biosurfactant concentration on surface tension
Besides, Table I summarizes the physicochemical properties of different biosurfactant producing microorganisms reported in the literature. Compared to the available literature, the CMC value of biosurfactant produced by Pseudomonas aeruginosa $\mathrm{KO} 9$ on glucose as the carbon source $(\mathrm{CMC}=85.82 \mathrm{mg} / \mathrm{L})$ is the lowest and it has better emulsification ability able to achieve an $E_{24}$ of $81 \%$ for diesel. This indicates strong surfactant activity comparable to that of other biosurfactants.

\section{B. Preliminary characterization of biosurfactant}

$5 \%(\mathrm{v} / \mathrm{v}) P$. aeruginosa KO9 $\left(10^{7}\right.$ cells $\left./ \mathrm{mL}\right)$ was inoculated in $100 \mathrm{~mL}$ GMS medium at a temperature of $30^{\circ} \mathrm{C}$ and an agitation rate of $180 \mathrm{rpm}$. After 3 days cultured, biosurfactant was extracted, purified and freeze-dried, light yellow powder was obtained, and the yield was $1.0866 \mathrm{~g} / \mathrm{L}$.

Fig. 2 shows FT-IR spectrum profile of dried biosurfactant produced by $P$. aeruginosa KO9 grown on 5\% (w/v) GMS medium. Preliminary analysis revealed that the biosurfactant produced by $P$. aeruginosa KO9 might be glycolipid primarily consisting of lipid and carbohydrate.

There are many reports on the isolation and surfactant production of different species of the genus Pseudomonas. However, the surfactants produced by $P$. aeruginos $a$ has been reported to produce more often lipid-carbohydrate compounds specially rhamnolipid-type biosurfactants. FT-IR spectrum of the KO9 biosurfactant disclosed a broad stretching peak at $3398 \mathrm{~cm}^{-1}$, characteristic of $\mathrm{O}-\mathrm{H}$ stretching vibrations of hydroxyl groups. The strong adsorption around $2928 \mathrm{~cm}^{-1}$ is expected to be the symmetric stretch $(v \mathrm{C}-\mathrm{H})$ of $\mathrm{CH}_{2}$ and $\mathrm{CH}_{3}$ groups of aliphatic chains. The corresponding symmetric stretch is seen at $2856 \mathrm{~cm}^{-1}$. Also, an characteristic peak displayed at $1738 \mathrm{~cm}^{-1}$ and a weak symmetric stretching peak around $1465 \mathrm{~cm}^{-1}$ indicate the presence of ester carbonyl groups $(\mathrm{C}=\mathrm{O}$ in $\mathrm{COOH})$ in the biosurfactant while the $\mathrm{C}-\mathrm{O}$ stretching bands at $1300-1000 \mathrm{~cm}^{-1}$ confirm the presence of the bonds formed between carbon atoms and hydroxyl groups in the chemical structures of the rhamnose rings. The absorption peak around $1050 \mathrm{~cm}^{-1}$ can be related to the presence of polysaccharide or polysaccharide-like substances in the biosurfactant

TABLE I. COMPARISONS OF PHYSICOCHEMICAL PROPERTIES OF DIFFERENT BIOSURFACTANTS

\begin{tabular}{|c|c|c|c|c|}
\hline Microorganism & Minimum ST (mN/m) & $E_{24}(\%)$ & CMC ( mg/L) & Reference \\
\hline Lactobacillus paracasei & 41.8 & Data not shown & 2500 & {$[10]$} \\
\hline $\begin{array}{c}\text { Rhodococcus } \\
\text { erythropolis 16 LM.USTHB }\end{array}$ & 31.9 & 63 & 287 & {$[11]$} \\
\hline Pseudomonas fluorescens & 32.0 & Data not shown & 290 & {$[12]$} \\
\hline Flavobacterium sp. MTN11 & 26.0 & Data not shown & 300 & {$[13]$} \\
\hline Pseudomonas aeruginosa SP4 & 29.0 & Data not shown & 200 & {$[7]$} \\
\hline Pseudomonas aeruginosa $\mathrm{KO} 9$ & 26.6 & 81 & 85.82 & Present article \\
\hline
\end{tabular}




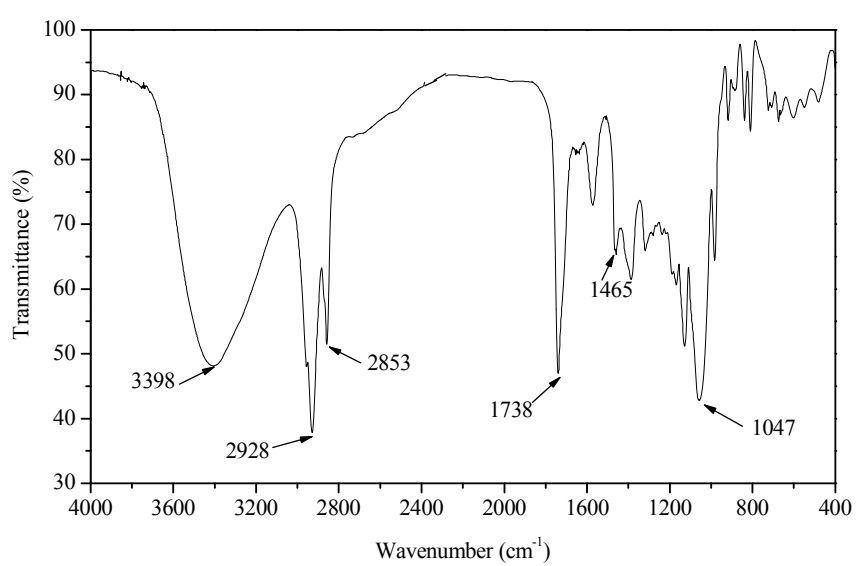

Figure2 FT-IR spectrum profile of dried biosurfactant produced by $P$. aeruginosa KO9 grown on GMS medium

\section{Effect of temperature, $\mathrm{pH}$ and salinity on biosurfactant} stability

Fig. 3a shows the effect of temperature on the surface tension and $\mathrm{E}_{24}$ of the biosurfactant produced from $\mathrm{P}$. aeruginosa KO9 as compared to the two synthetic commercial surfactants, SDS and CTAB. The results show that the three tested surfactants were able to withstand $90{ }^{\circ} \mathrm{C}$ up to $2 \mathrm{~h}$ without a reduction in surface tension. However, emulsification capacity of biosurfactant was more stable than SDS and CTAB. In addition, the heat tolerance of the tested surfactants was studied by autoclaving at $121{ }^{\circ} \mathrm{C}$ for $15 \mathrm{~min}$. For both the biosurfactant and CTAB, the surface tension and emulsion index remained unchanged, indicating that both surfactants possess excellent thermostable. In the case of SDS, the ST increased remarkably from $29.82 \mathrm{mN} / \mathrm{m}$ to 36.75 $\mathrm{mN} / \mathrm{m}$ and the $\mathrm{E}_{24}$ decreased from $70.2 \%$ to $51.8 \%$ after the heat treatment. The result suggested that deterioration of SDS occurred at a temperature of $121{ }^{\circ} \mathrm{C}$.

Fig. $3 b$ shows the effect of $\mathrm{pH}$ on $\mathrm{ST}$ and $\mathrm{E}_{24}$ in the presence of the biosurfactant, as compared to the two commercial surfactants. As can be seen in Fig. 3b, both SDS and $\mathrm{CTAB}$ were more stable throughout the studied range of $\mathrm{pH}$. In contrast, the activity of biosurfactant and its emulsification ability was affected by the $\mathrm{pH}$. When the $\mathrm{pH}$ was under 5 , the biosurfactant activities were above $30 \mathrm{mN} / \mathrm{m}$. Correspondingly, the emulsification ability was limited to the acid $\mathrm{pH}$ and emulsification indexes were less than 55\%. However, both biosurfactant activity and emulsification capacity was relatively stable between $\mathrm{pH} 6$ and $\mathrm{pH} 11$.

Fig. 3c demonstrates the effect of addition of $\mathrm{NaCl}$ on the surface tension and emulsification capacity of the surfactants. As it is shown, negligible changes were occurred on the two commercial surfactants with an increase of $\mathrm{NaCl}$ concentration, whereas the surface tension and emulsification capacity of biosurfactant remained constant throughout the studied range of salinity.

When compared to the commercial surfactants, the biosurfactant possessed superior properties in both heat and salinity stabilities, and it was quite constant between $\mathrm{pH} 6$ and $\mathrm{pH} 11$.These findings suggest that the robust characteristics of the crude biosurfactant are suitable for applications under extreme conditions, such as in microbial enhanced oil recovery (MEOR) and in the bioremediation of a polluted environment. Moreover, this biosurfactant has great potential for biomedical applications due to its thermostability even after being submitted to autoclave sterilization.
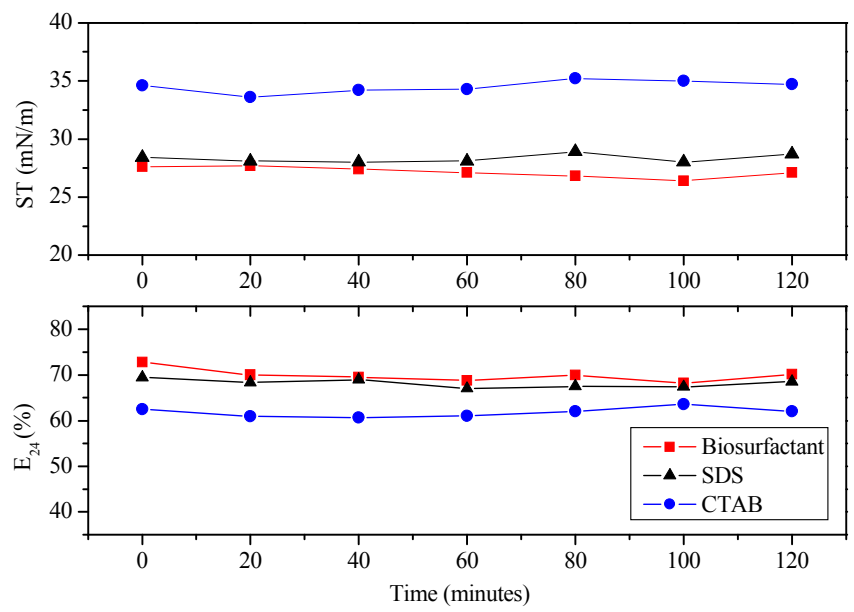

a
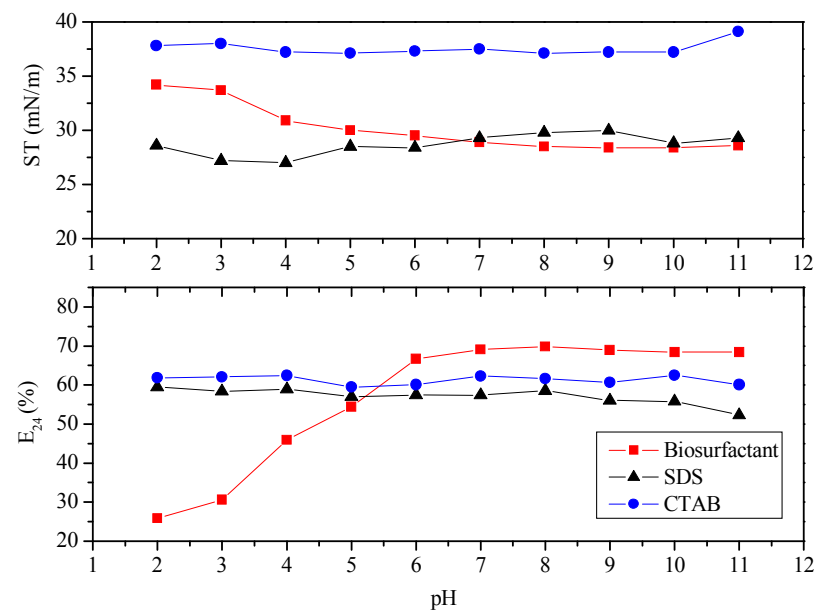

b
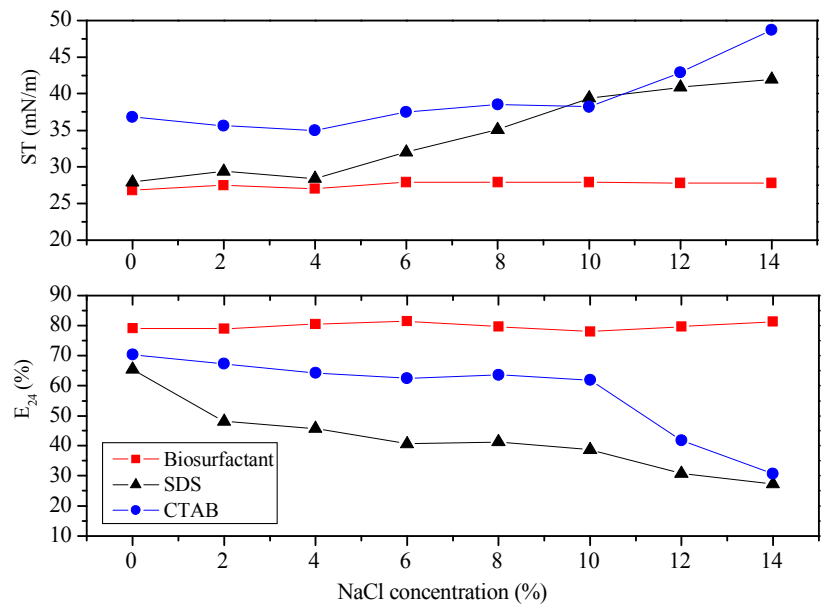

c

Figure 3 Stability of the biosurfactant as compared with SDS and CTAB. (a) $\mathrm{ST}$ and $\mathrm{E}_{24}$ of surfactants after heat treatment at $90{ }^{\circ} \mathrm{C}$ with different heating times. (b) Effect of $\mathrm{pH}$ on surface activity of surfactants. (c) Effect of salinity on surface activity of surfactants. 


\section{CONCLUSIONS}

In this study, the crude biosurfactant produced from $P$. aeruginosa KO9 was chemically characterized as glycolipid mainly consisting of lipid and carbohydrate. It was able to reduce the surface tension of pure water to $26.6 \mathrm{mN} / \mathrm{m}$ and achieve the $\mathrm{E}_{24}$ of $81 \%$ for diesel, besides the $\mathrm{CMC}$ was found to be $85.82 \mathrm{mg} / \mathrm{L}$. When compared to synthetic surfactants, including sodium dodecyl sulfate (SDS) and cetyltrimethyl ammonium bromide (CTAB), the crude biosurfactant showed excellent stability over a wide range of $\mathrm{pH}$ and temperatures and high salt concentrations which suggest that it is suitable for use in oil fields, biomedical applications and removal of oil pollutions.

\section{ACKNOWLEDGMENTS}

We thank Mr Li (Oasis Environment \& Safety Technology Co., Ltd.) for supplying soil samples from Karamay Oilfield. This study was supported by The Research \& Technology Development Project of China National Petroleum Corporation (No. 2008D-4704-2).

\section{REFERENCES}

[1] J.D. Van Hamme, A. Singh, O.P. Ward, "Physiological aspects: Part 1 in a series of papers devoted to surfactants in microbiology and biotechnology," Biotechnology Advances. vol. 24, pp. 604-620, 2006.

[2] A. Singh, J.D. Van Hamme, O.P. Ward, "Surfactants in microbiology and biotechnology: Part 2. Application aspects," Biotechnology Advances. vol. 25, pp. 99-121, 2007.

[3] I.M. Banat, R.S. Makkar, S.S. Cameotra, "Potential commercial applications of microbial surfactants," Applied and Environmental Microbiology. vol. 53, pp. 495-508, 2000.
[4] S.S. Cameotra, R.S. Makkar, "Recent applications of biosurfactants as biological and immunological molecules," Current Opinion in Microbiology. vol. 7, pp. 262-266, 2004.

[5] I.M. Banat, R.S. Makkar, S.S. Cameotra, "Potential commercial applications of microbial surfactants," Applied Microbiology Biotechnology. vol. 53, pp. 495-508, 2000.

[6] M.G. Healy, C.M. Devine, R. Murphy, "Microbial production of biosurfactants," Resources, Conservation and Recycling. vol. 18, pp. 41-57, 1996.

[7] O. Pornsunthorntawee, P. Wongpanit, S. Chavadej, M. Abe, R. Rujiravanit, "Structural and physicochemical characterization of crude biosurfactant produced by Pseudomonas aeruginosa SP4 isolated from petroleumcontaminated soil," Bioresource Technology. vol. 99, pp. 1589-1595, 2008.

[8] T.B. Lotfabad, M. Shourian, R. Roostaazad, A.R. Najafabadi, M.R. Adelzadeh, K.A. Noghabi, "An efficient biosurfactant-producing bacterium Pseudomonas aeruginosa MR01, isolated from oil excavation areas in south of Iran," Colloids and Surfaces B: Biointerfaces.vol. 69, pp. 183-193, 2009.

[9] D.G. Cooper, B.G. Goldenberg, "Surface-active agents from two Bacillus species," Applied and Environmental Microbiology. vol. 53, pp. 224-229, 1987.

[10] E.J. Gudiňa, J.A. Teixeira, L.R. Rodrigues, "Isolation and functional characterization of a biosurfactant produced by Lactobacillus paracasei," Colloids and Surfaces B: Biointerfaces. vol. 76, pp. 298-304, 2010.

[11] Z. Sadouk, H. Hacene, A. Tazerouti, "Biosurfactants Production from Low Cost Substrate and Degradation of Diesel Oil by a Rhodococcus Strain," Oil \& Gas Science and Technology - Rev. IFP. vol. 63, pp. 747-753, 2008.

[12] M. Abouseoud, A. Yataghene, A. Amrane, R.Maachi, "Effect of pH and salinity on the emulsifying capacity and naphthalene solubility of a biosurfactant produced by Pseudomonas fluorescens," Journal of Hazardous Materials. vol. 180, pp. 31-136, 2010.

[13] A.A. Bodour, C. Guerrero-Barajas, B.V. Jiorle, M.E. Malcomson, A.K. Paull, A. Somogyi, L.N. Trinh, R.B. Bates, R.M. Maier, "Structure and Characterization of Flavolipids, a Novel Class of Biosurfactants Produced by Flavobacterium sp. Strain MTN11," Applied and Environmental Microbiology. vol. 70, pp. 114-120, 2004. 